\title{
A New Species of the Genus Halectinosoma Vervoort, 1962 (Copepoda: Harpacticoida: Ectinosomatidae) from the East Coast of Korea, with a Key to Species of the Curticorne-Group
}

\author{
Hyun Woo Bang \\ Division of Biomedical Engineering \& Healthcare, Mokwon University, Daejeon 35349, Korea; \\ hbang@mokwon.ac.kr; Tel.: +82-42-829-7583 \\ http://zoobank.org/urn:lsid:zoobank.org:pub:9883012F-02E0-4EAA-A578- \\ D9CA52A1AE0D
}

Received: 25 September 2020; Accepted: 21 October 2020; Published: 29 October 2020

\begin{abstract}
A new species of genus Halectinosoma Vervoort, 1962 was collected from the east coast of Korea. The genus Halectinosoma comprises about 70 species, but only three species have previously been reported in East Asia. Halectinosoma munmui sp. nov. is morphologically most closely related to H. langi Wells 1967 from Inhaca Island, Mozambique, and H. oblongum (Kunz, 1949) from Heligoland island, Germany, however clearly distinguishable from it based on the following morphological characteristics: 5-segmented and elongated female antennule, mandible gnathobase without seta, about 5.6 times as long as the greatest width of the basis of the maxilliped, and outer seta of the P5 endopodal lobe longer than the inner seta. A key to species of the curticorne-group of Halectinosoma is provided.
\end{abstract}

Keywords: benthic harpacticoida; meiofauna; East Asia; Ectinosomatidae; taxonomy

\section{Introduction}

To date, the biodiversity of harpacticoid copepods on the coast of Korea is poorly documented compared to other countries such as the United States, countries in the Caribbean Sea, Japan and Europe [1], because the history of taxonomic research is relatively short and there are not many studies and research [2]. However, the list of reported species along the coast of Korea is expected to grow very fast as many new and unrecorded species are discovered each year through various taxonomic studies [1], including the project of 'Discovery of Korean Indigenous Species', which have been conducted since 2006 .

Halectinosoma Vervoort, 1962 is one of the most divergent genera in the family Ectinosomatidae Sars, 1903 and is, to date, composed of 69 species [3]. Although the genus Halectinosoma is one of the largest groups in the family Ectinosomatidae, only three species of Halectinosoma have been reported in East Asia [4]: H. arenicola (Rouch, 1962) and H. perforatum Itô, 1981 in Japan (H. japonicum (Miura, 1964) was also reported but was considered as species inquirenda by Karanovic and Pesce [5]), and H. perforatum and H. foveolata Kim, Jung and Yoon, 2017 in Korea [4]. Most recently, Sciberras et al. [3] organized and reevaluated several confused and complex species of Halectinosoma during the reporting of the new species H. parejae from Argentina, and also updating the key to genera of the family Ectinosomatidae.

As part of an ongoing taxonomic study of harpacticoid copepods along Korean coasts, harpacticoid copepods have been collected. Here, I describe Halectinosoma munmui sp. nov. from sediments of the east coast of Korea based on female morphology and provide an updated key to the species of Halectinosoma. 


\section{Materials and Methods}

Samples were collected from Bong-gil Beach, Gyeongju, Korea ( $\left.35^{\circ} 44^{\prime} 21.1^{\prime \prime} \mathrm{N}, 129^{\circ} 29^{\prime} 03.0^{\prime \prime} \mathrm{E}\right)$ in January 2019 (Figure 1). Samples were taken with a hand net, fixed with $70 \%$ ethanol. Meiofauna was extracted from the sediment by Ludox centrifugation [6]. Copepods were sorted under a Leica S APO stereo zoom microscope and stored in $70 \%$ ethanol. Samples were dissected in lactic acid, and the dissected appendages were permanently mounted on slides in lactophenol. Preparations were sealed with transparent nail varnish. All drawings were prepared using a Leica DM 2500 differential interference contrast microscope. Specimens were deposited at the National Institute of Biological Resources (NIBR) of Korea. The descriptive terminology is adopted from Huys et al. [7]. Abbreviations used in the text are: A1, antennule; A2, antenna; ae, aesthetasc; enp, endopod; exp, exopod; P1-P6, first to sixth thoracopod; $\exp (\operatorname{enp})-1(2,3)$ to denote the proximal (middle, distal) segment of a ramus. Scale bars in figures are indicated in $\mu \mathrm{m}$.

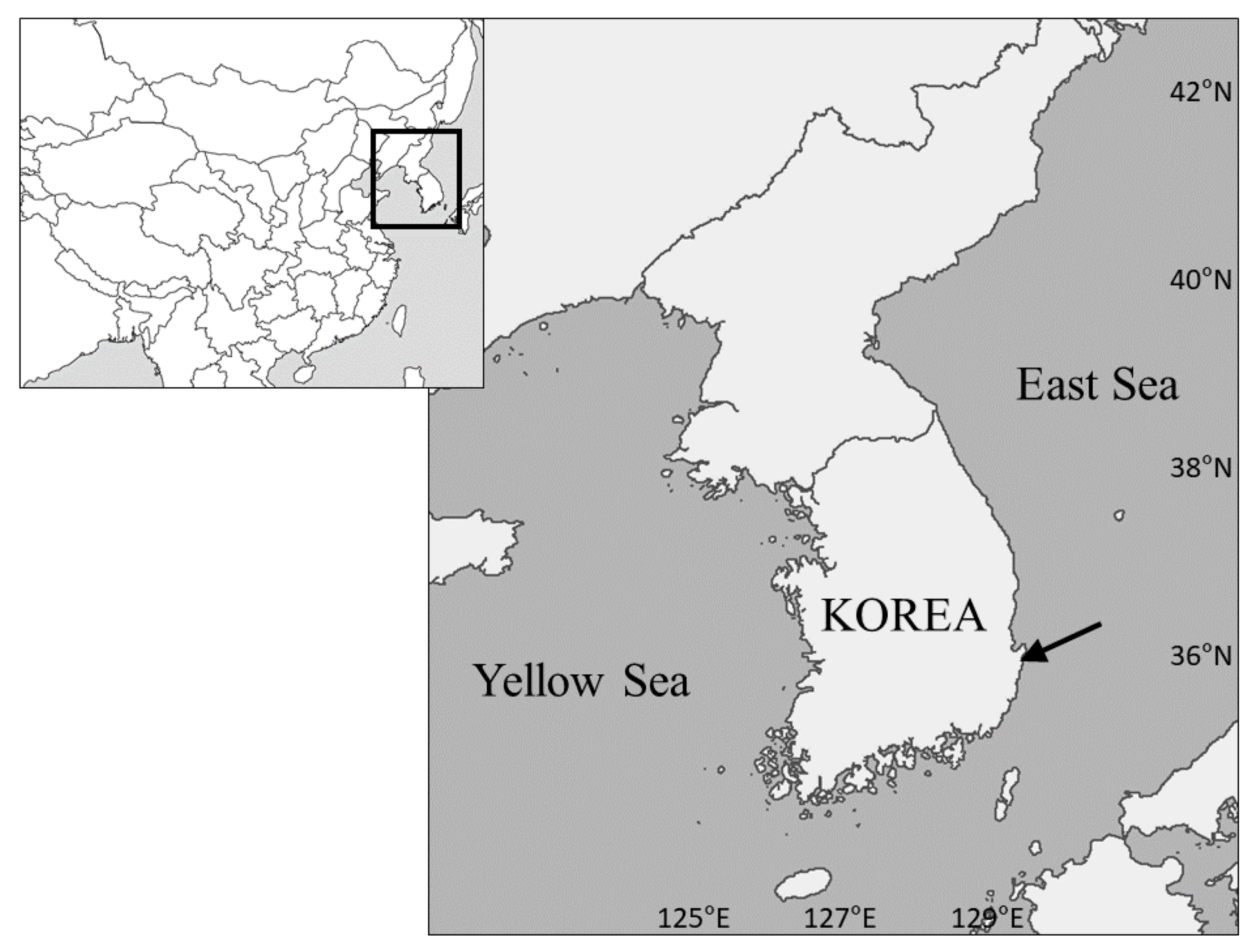

Figure 1. The sampling site. Type locality indicated by an arrow (Bong-gil Beach, Gyeongju, Korea).

\section{Results-Systematics}

Order Harpacticoida Sars, 1903.

Family Ectinosomatidae Sars, 1903.

Genus Halectinosoma Vervoort, 1962.

Halectinosoma munmui sp. nov.

Type locality. Bong-gil Beach, Gyeongju, Korea $\left(35^{\circ} 44^{\prime} 21.1^{\prime \prime} \mathrm{N}, 129^{\circ} 29^{\prime} 03.0^{\prime \prime} \mathrm{E}\right)$.

Material examined. Holotype 19(ZCIVIV0000004256) dissected on 9 slides. Paratypes 11우(ZCIVIV0000004249) in 70\% ethanol, vial. All from the type locality, collected by H.W. Bang and H. Moon in January 2019.

Etymology. The species name refers to the type locality; Bong-gil Beach is near the Underwater Tomb of King Munmu of the Korean kingdom of Silla, the world's only underwater tomb.

Female. Total body length: $650 \mu \mathrm{m}(\mathrm{n}=10$; range: $612-698 \mu \mathrm{m})$, measured from anterior margin of rostrum to posterior margin of caudal rami. Largest width measured at posterior margin of cephalic shield: $104 \mu \mathrm{m}$. Habitus (Figure 2A) elongated, fusiform. Urosome slightly narrower than prosome. 


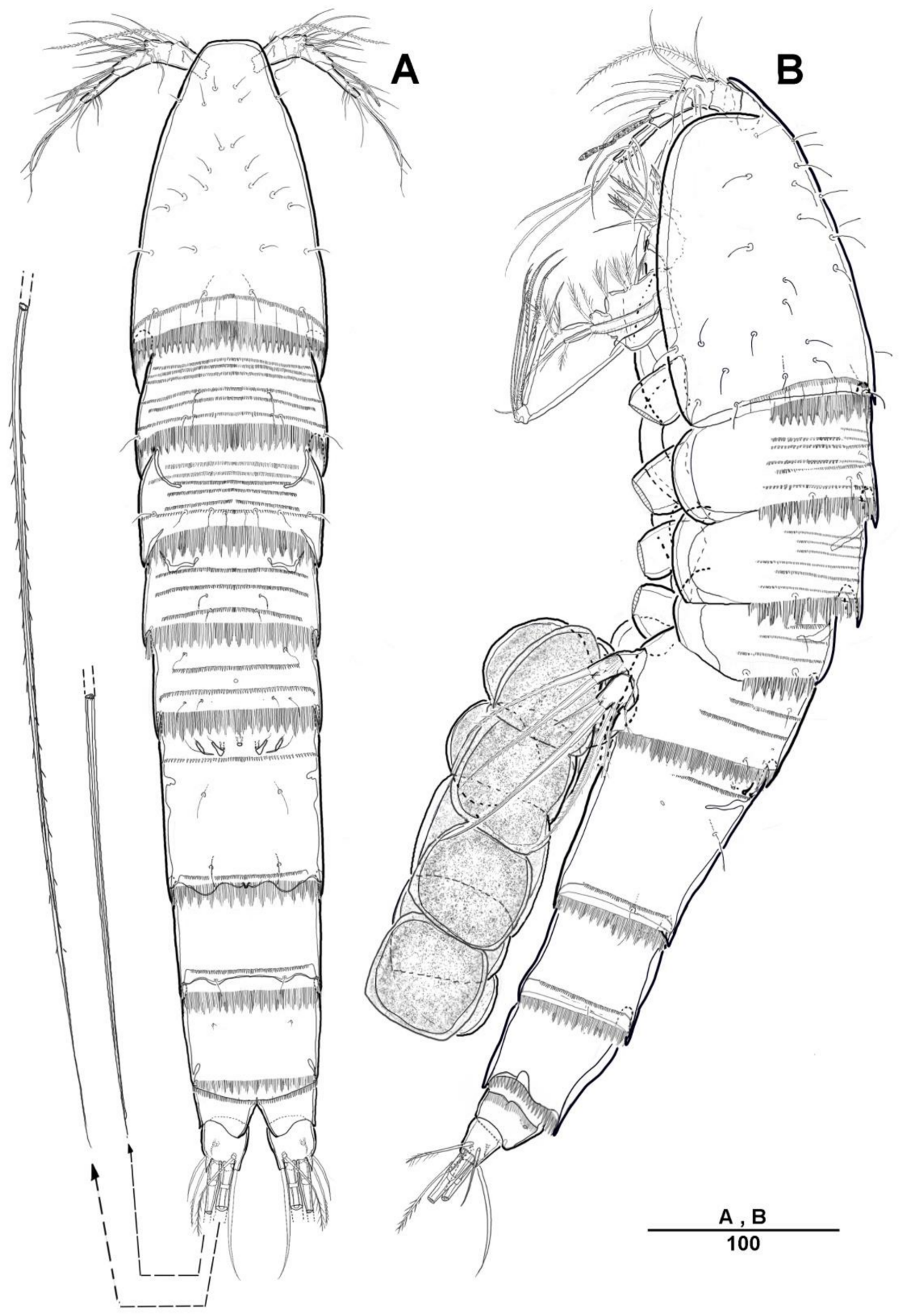

Figure 2. Halectinosoma munmui sp. nov. holotype female. (A) Habitus, dorsal; (B) habitus, lateral.

Cephalothorax gradually tapering anteriorly, dorsal surface with minute spinule row near posterior margin, posterior margin with deeply serrate hyaline frill, sensillar pattern on cephalothorax and body somites as figured in Figure 2A. Rostrum broadly rounded and fused at base with cephalothorax. Pedigerous somites with several transverse rows of spinules dorsally, serrate posteriorly as cephalothorax; pleural areas well developed, spinule rows, pores and sensilla as figured.

Urosome (Figure 2A,B) 5-segmented, comprising P5-bearing somite, genital double-somite and 3 free abdominal somites. All urosomites with spinules around posterior margin. Genital double-somite (Figure 3B) completely fused internally and externally, without distinct dorsal surface ridge, 
original segmentation marked by lateral and ventral subcuticular transverse ridges; transverse rows of minute spinules in lateral and dorsal surfaces, rows of minute spinules either side of genital slit, and hyaline frill along the distal margin. Genital field positioned near ventrally with a large copulatory pore, and P6 represented by narrow transverse plate, with a protuberance bearing one bare seta. Anal somite (Figure 3C) deeply cleft medially, with well-developed hyaline frill along posterior margin, pseudoperculum well developed.

Caudal ramus (Figure 3C,D) as long as broad, with seven setae: seta I shortest, bare; seta II bare; seta III slightly pinnate; seta IV bare and long; V sparsely bipinnate, about 2.0 times as long as seta IV; seta VI longer than seta III, bare and slender; seta VII bi-articulate at base and plumose, inserted on inner margin opposite seta I.

Antennule (Figure 4A) short and slender, 5 -segmented. Segment 1 with two rows of minute spinules and few long setules around anterior margin. Segment 3 with aesthetasc fused basally to seta and set on pedestal. All setae naked except for one pinnate seta on segments 1 . Armature as follows: 1-[1], 2-[10], 3-[5 + (1+ ae)], 4-[0], 5-[8 + acrothek]. Apical acrothek consisting of 3 long setae.

Antenna (Figure 4B). Coxa small. Basis longer than wide, with of long setules on abexopodal margin. Exopod small, 3-segmented; exp-1 longer than exp-2, without seta; exp-2 shortest with one bare seta; exp-3 longest, few spinules present around distal corner, with two pinnate spines apically. Endopod 2-segmented. Enp-1 slightly longer than basis, without ornamentation; enp-2 with strong spinules near proximal corner and near posterior margin; lateral armature arising in proximal third, consisting of one unipinnate and one bipinnate spine; apical armature consisting of two unipinnate and two bipinnate setae, and one short bare and two geniculate setae.

Mandible (Figure 4C) with blunt molar-like gnathobase bearing five small edgeless teeth around ventral distal margin, and bidentate tooth at near dorsal corner, without seta. Palp well-developed, biramous. Basis elongate, with three pinnate setae inserted at distal margin. Endopod 1-segmented, rectangular, and with a row of setules on lateral margin, with one lateral and four apical naked setae, of which two distal fused at base. Exopod 1-segmented, small, with one short spinulose seta, and two plumose setae fused basally to segment.

Maxillule (Figure 4D,E). Praecoxal arthrite with four strong spinulose spines, anterior surface with two small naked setae. Coxa apparently incorporated into the praecoxa, represented by one short cylindrical endite bearing one long pinnate seta. Basis with spinules along inner margin, with four spinulose setae distally. Endopod trilobate, with eight naked setae. Exopod 1-segmented, small, with two bare setae.

Maxilla (Figure 4F) non-prehensile, comprising syncoxa, allobasis and endopod. Syncoxa with three endites: proximal endite rudimentary, with one pinnate spine and two bipinnate setae; middle endite small, with two pinnate setae; distal endite with one bipinnate seta and one unipinnate spine. Allobasis longer than syncoxa, with armed with two pinnate setae and one unipinnate spine lateral margin. Endopod composed of two geniculate, two pinnate long setae and one small bare seta.

Maxilliped (Figure 4G). Syncoxa short, with one long pinnate seta. Basis elongated, about 5.6 times as long as wide, with double row of long setules along outer margin, inner margin spinulose. Endopod about 5.8 times as long as wide, with one pinnate seta laterally, one spinulose seta subdistally, and apical armature consisting of two naked setae.

Swimming legs 1-4 (Figure 5A,B and Figure 6A,B) with intercoxal sclerite and praecoxae, both without ornamentation. Coxae and bases with surface ornamentations of spinules as figured. All swimming legs with three-segmented exopods and endopods, and endopods typically longer than exopods. Exp-1 and exp-2 with hyaline frill on anterior distal margins. Enp-1 with secretory pore on anterior surface near distal margin. 


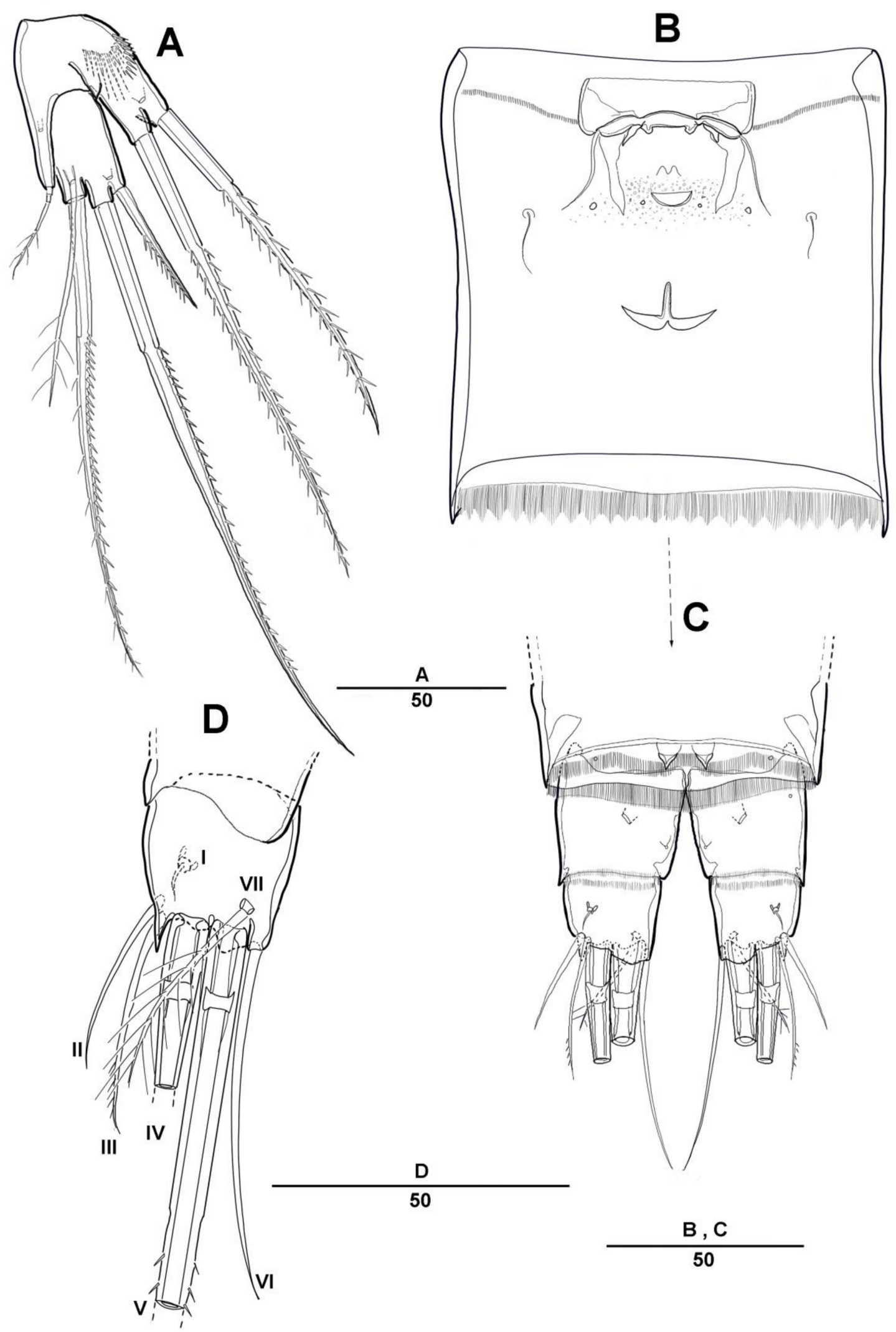

Figure 3. Halectinosoma munmui sp. nov. holotype female. (A) P5, anterior; (B) genital field, ventral; (C) anal somite and caudal rami, ventral; (D) caudal ramus, dorsal. 


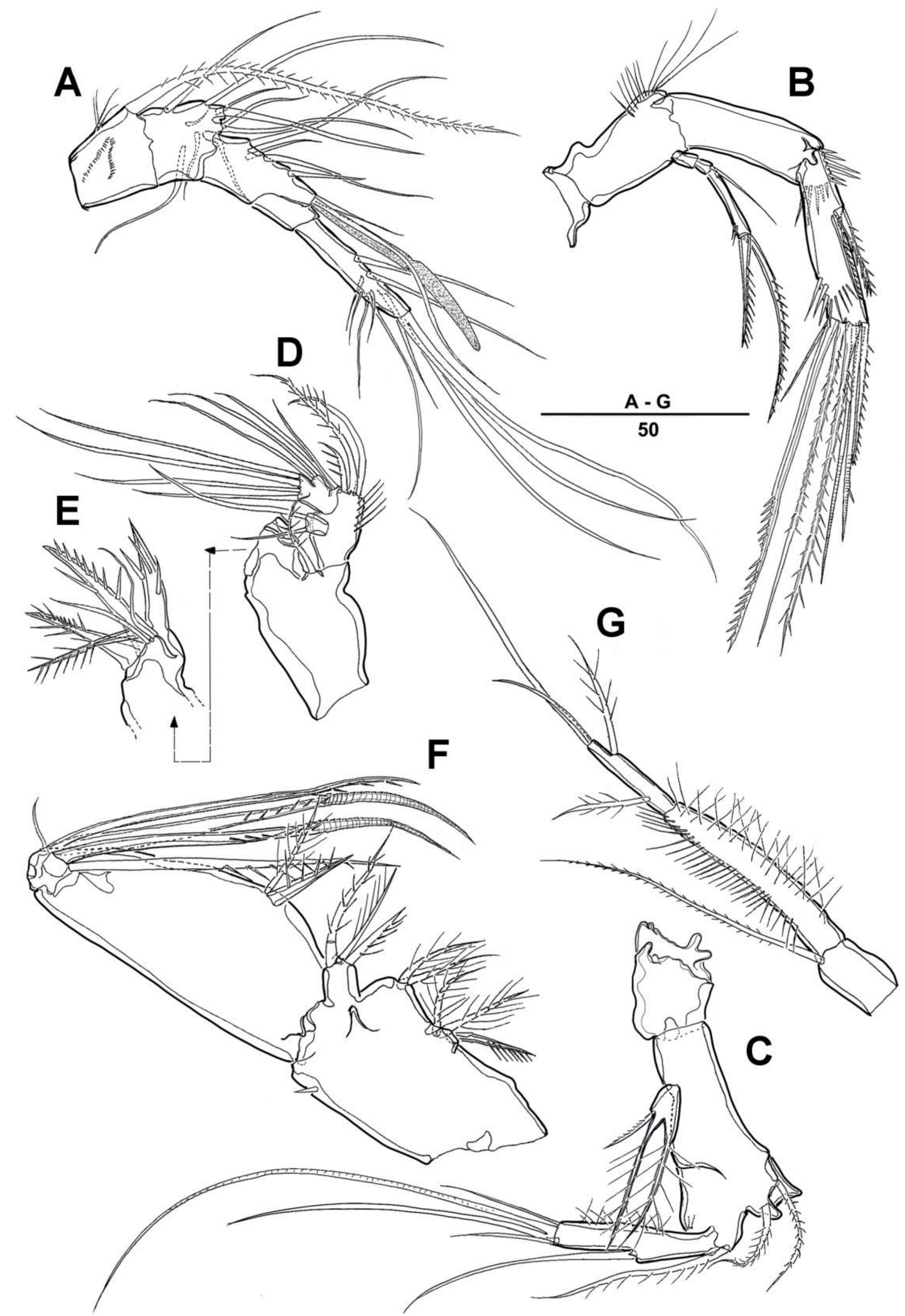

Figure 4. Halectinosoma munmui sp. nov. holotype female. (A) Antennule; (B) antenna; (C) mandible; (D) maxillule; (E) maxillule, praecoxal arthrite; (F) maxilla; (G) maxilliped. 


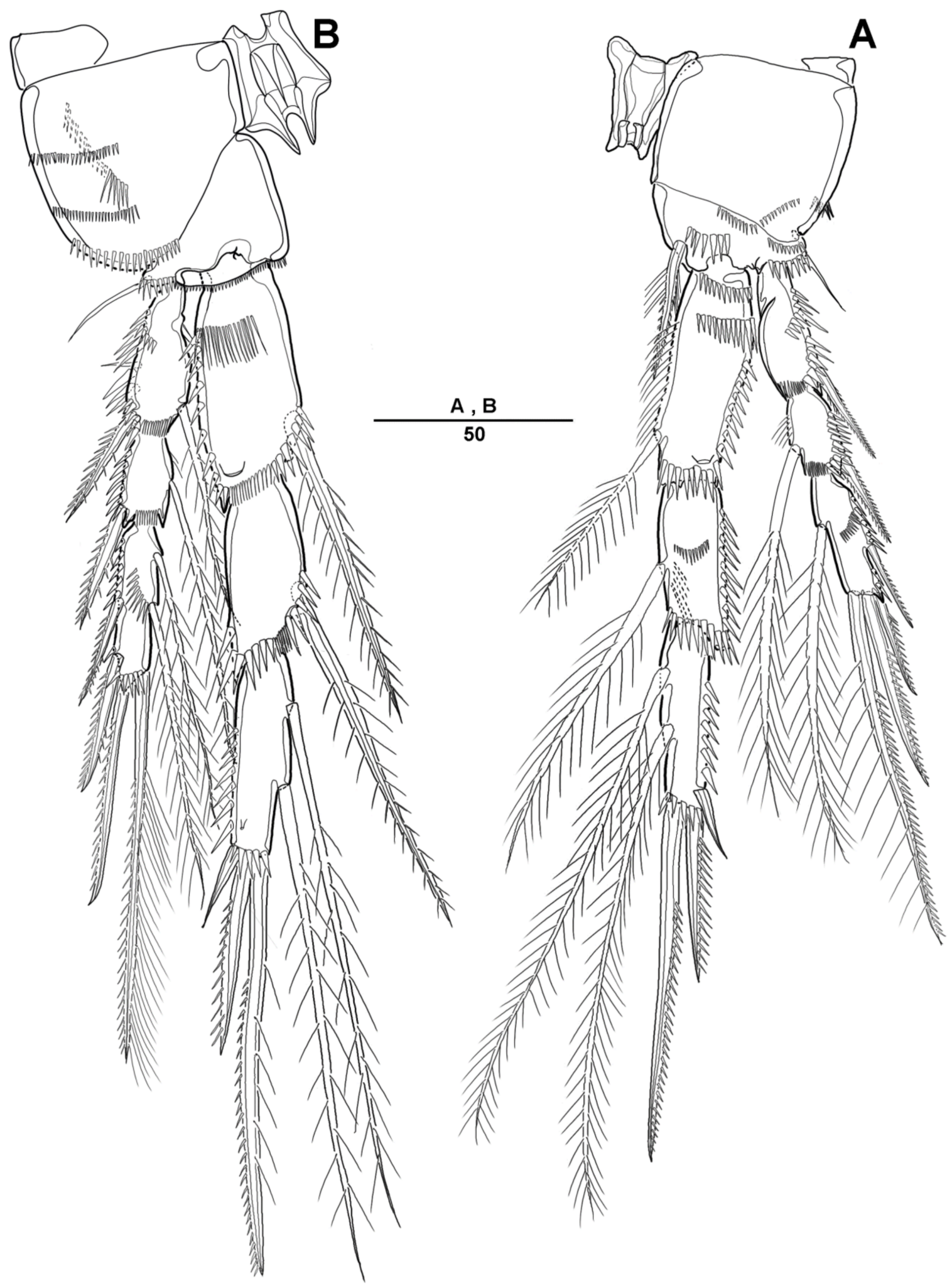

Figure 5. Halectinosoma munmui sp. nov. holotype female. (A) P1, anterior; (B) P2, anterior. 


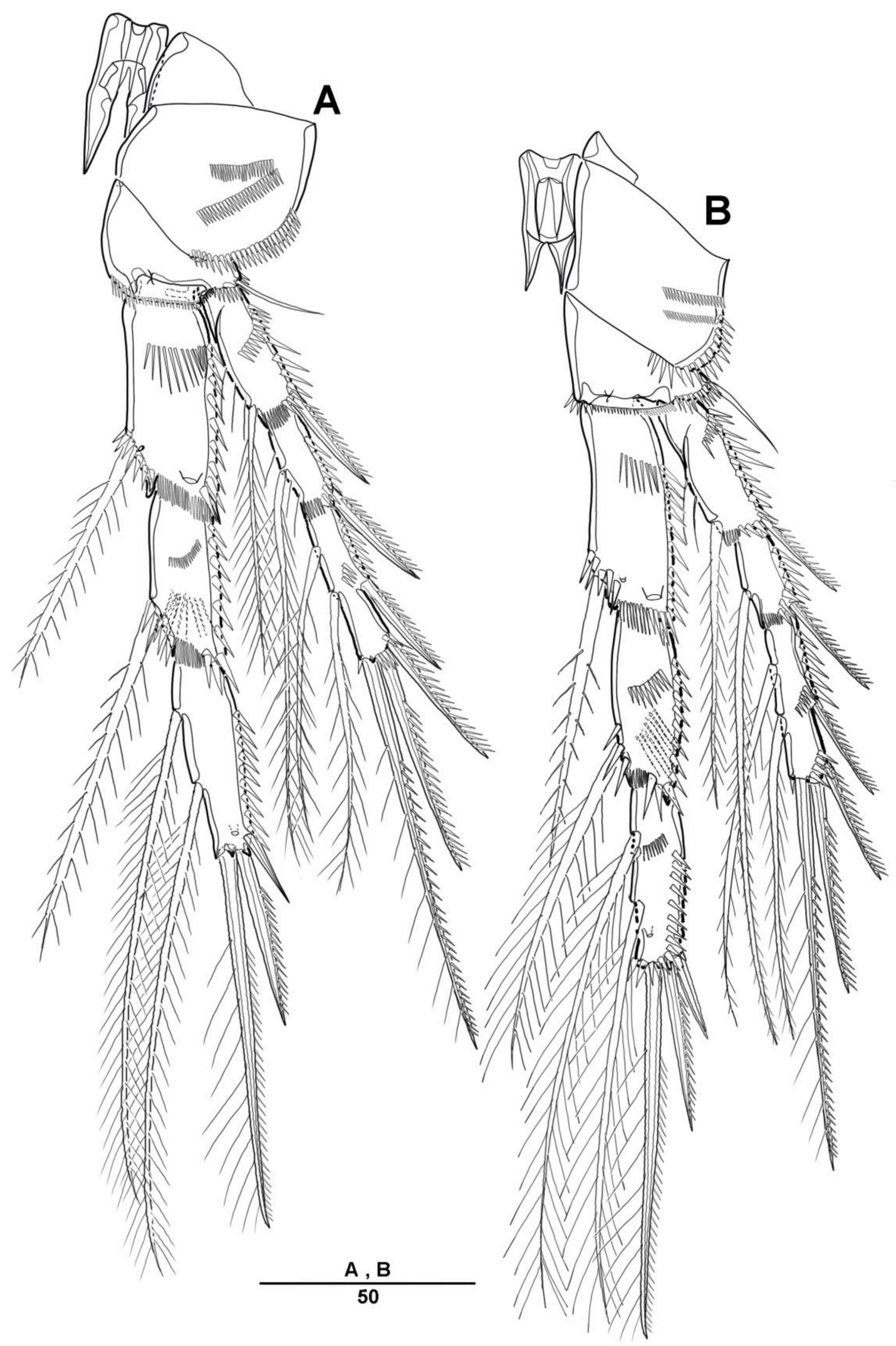

Figure 6. Halectinosoma munmui sp. nov. holotype female. (A) P3, anterior; (B) P4, anterior.

P1 (Figure 5A). Intercoxal sclerite small, without ornamentation. Praecoxa well developed. Coxa large, as long as wide, and with spinular rows on anterior surface. Basis with 1 outer bare and 
1 inner strong pinnate spine, anterior surface covered with spinules as figured. Exp- 1 without inner seta; exp-2 with one outer stout pinnate spine and one long, plumose, inner seta; exp-3 with five setal elements. Enp-1 longest, with inner plumose seta, and with stout spinules distal and outer margins and long setules along inner margins; enp-2 with one inner plumose seta and with spinules distally on outer margins, row of spinules on anterior and posterior surfaces; enp-3 with stout spinules along outer margins, with two long plumose inner setae, two well-developed unipinnate spines, and one small naked outer spine.

P2-P4 (Figures 5B and 6A,B). Coxae ornamented with spinular rows on anterior surface and near outer distal margin. Basis triangular, with stout spinules along outer margin, hyaline frill on distal margins, and with naked outer seta. Rami 3-segmented, outer margins of segments with coarse spinules; exp-1 and exp-2 with one plumose inner seta; enp-3 one with pore on anterior surface, P3-P4 enp-2 with row of spinules on anterior and posterior margins.

Armature formula for swimming legs:

$\begin{array}{lll} & \text { Exopod } & \text { Endopod } \\ \text { P1 } & 0.1 .122 & 1.1 .221 \\ \text { P2 } & 1.1 .122 & 1.1 .221 \\ \text { P3 } & 1.1 .222 & 1.1 .221 \\ \text { P4 } & 1.1 .222 & 1.1 .221\end{array}$

P5 (Figure 3A) with separate exopod and baseoendopod. Exopod about 1.8 times as long as broad, with one small pore on anterior surface, and with three terminal setae; innermost shortest, middle seta longer than outer seta; anterior surface with one plumose seta at the insertion site. Baseoendopod with two pores on anterior surface and row of spinules on anterior surface and large spinules on posterior surface; large setophore bearing slender triarticulate outer basal seta; endopodal lobe reaching halfway along inner margin of exopod, with two spinulose setae on distal margin.

Male. Unknown.

\section{Discussion}

Lang [8] separated the genus Ectinosoma into two subgenera, Ectinosoma and Halectinosoma, and divided the subgenus Halectinosoma into a sarsi- (P2-P4 exp-3 with three outer spines; type species, E. sarsi Boeck, 1872) and a curticorne-groups (P4 exp-3 with two outer spines; type species, E. curticorne Boeck, 1872). Later, the subgenus Halectinosoma was upgraded to genus level by Verboort [9] and Lang [10]. As the genus Halectinosoma has a number of taxonomically complex and unresolved issues [11], Clément and Moore have tried to solve the problems of the genus Halectinosoma through three consecutive studies. In the first study, Clément and Moore [12] regarded the type species of the genus, Halectinosoma sarsi Boeck, 1872 as species incertae sedis. After that, Clément and Moore [13] proposed a herdmani-group in the genus Halectinosoma based on a number of features and provided a key for the identification of the group's females, however, due to several taxonomic ambiguities, only the herdmani-group is now recognized among the three groups [4]. In the third study, Clement and Moore [14] provided a revision of the genus Halectinosoma, presenting four new species of the North Atlantic and Arctic regions.

Kim et al. [4] summarized the morphological characteristics of 70 species of Halectinosoma, including a new species H. foveolata Kim, Jung and Yoon, 2017. According to the arrangement of Kim et al., the following characters are important in distinguishing the species within the genus Halectinosoma: (1) the number of segments and shape of female antennule; (2) the armature complement of the antennal exopod; (3) the morphology of the mandibular gnathobase; (4) the armature formulae of P1 and P4; (5) the shape and size of the female P5 endopodal lobe; and (6) the ratio of length and width of female P5 exopod and number of seta.

Sciberras et al. [3] divided a total of 69 species of Halectinosoma into two groups, using a swimming leg armature formula: ancestral condition and derived condition. H. longicorne (T. and A. Scott, 
1896) and H. concinnum (Akatova, 1935) were not included due to insufficient data. According to Sciberras et al., Pseudobradya lanceta Coull, 1986 was transferred to Halectinosoma Vervoort, 1962 as H. lancetum (Coull, 1986), and H. arenicola (Rouch, 1962) sensu Itô (1973) from the Japanese coast was reassigned to a distinct specific status as H. pseudarenicola. In addition, Halectinosoma spinicauda Wells, 1961, H. pterinum Moore, 1974 and H. paraspinicauda Bodin, 1979 are also removed from Halectinosoma and placed into Pseudobradya Sars, 1904 as P. spinicauda (Wells, 1961), P. pterina (Moore, 1974) and P. paraspinicauda (Bodin, 1979), respectively, and H. littorale (Nicholls, 1939) is to be considered a species inquirenda in Pseudobradya.

The specimens from the east coast of Korea were assigned to the genus Halectinosoma based on the diagnostic characters defined by Wells [15] and Sciberras et al. [3]: body fusiform; antennule 5-segmented in the female and without a pigment spot; antenna with 3-segmented exopod; mandibular basis and exopod with three setae each; maxilla with a slight angle between the syncoxa and allobasis; maxilliped elongated and slender and endopod with 4 setae; legs 1-4 with 3-segmented rami and exp-3 with two outer spines; and P5 with three marginal setae and one seta on anterior surface.

According to Lang [8], the new species belongs to the curticorne-group based on the P4 exopod that bears with two outer spines. Halectinosoma munmui sp. nov. is closely related to H. langi Wells, 1967 and H. oblongum (Kunz, 1949) based on the combination of four characters: (1) P1 exp-3 with two outer spines, (2) P1-P4 enp-3 with 5 setae, (3) inner seta of the P5 endopodal lobe subequal or inner seta slightly longer than the outer one, and (4) the first segment of A1 without a darkly pigmented patch. However, H. munmui sp. nov. can be differentiated from the congeners by (1) a 5-segemented and elongate antennule in the female, whereas $H$. oblongum has a 6-segmented female antennule and (2) a mandible gnathobase without seta. In contrast, $H$. langi has two setae on the mandibular gnathobase, (3) the maxillipedal basis is about 5.6 times longer than its broadest width (8.0 times in H. oblongum and 4.0 times in H. langi), and (4) the outer seta of the P5 endopodal lobe is longer than the inner seta. Including Halectinosoma munmui sp. nov., the number of valid species in the genus Halectinosoma has increased to 70. The genus Halectinosoma is divided into three groups, namely, sarsi-, curticorne-, and herdmani-groups, among which the new species belongs to the curticorne-group. However, there are still many uncertainties and differences. Sciberras et al. [3] presented a key to species of 17 species of Halectinosoma that deviated from the primitive condition of the swimming legs, which includes 14 species of the curticorne-group.

A key to the species of the curticorne-group of Halectinosoma is provided. It is amended from Wells [15] and Sciberras et al. [3]. 
1. P2-P4 exp-3 with three outer spines 2

P4 exp-3 with two outer spines

3 curticorne-group

2. Body and rostrum elongated; P3-P4 exopod-3 with three inner setae; antenna exopod-1 with a short seta and a row of spinules. herdmani-group

These characters not combined sarsi-group

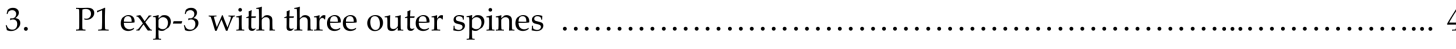

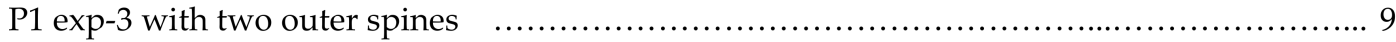

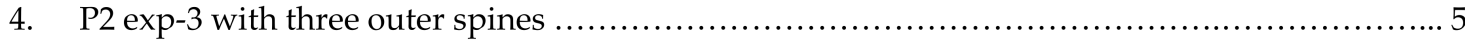

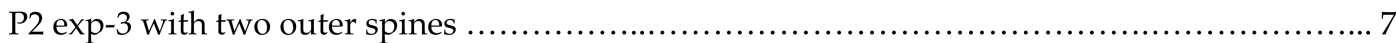

5. P2-P4 exp-3 with one inner seta; $\mathrm{P} 4$ enp-3 with one inner seta ........... H. erythrops (Brady, 1880)

P2-P3 exp-3 with two inner setae; P4 exp-3 with three inner setae; P4 enp-3 with two inner setae

6. Cephalothorax with a pigmented patch H. gothiceps (Giesbrecht, 1881) Pigmented patch on cephalothorax absent H. paragothiceps Clément and Moore, 2007

7. P3-P4 exp-3 with three inner setae .... 8 P3-P4 exp-3 with two inner setae .......... H. parejae Sciberras, Huys, Bulnes and Cazzaniga 2018

8. Inner part of female P5 endopodal lobe produced into globular extension

Distal margin of female P5 endopodal lobe virtually straight H. smirnovi (Chislenko, 1967

9. P1-P4 enp-3 with outer spine 10 P1-P4 enp-3 without outer spine H. tenuireme (Scott and Scott, 1896)

10. P4 exp-3 with two inner setae . .11 P4 exp-3 with one inner seta ...... H. gracile (Scott and Scott, 1896)

11. P3 exp-3 with two inner setae .12 P3 exp-3 with three inner setae H. islandicum Apostolov, 2007

12. P5 endopodal lobe inner seta about four times as long as outer one....... H. abyssicola Bodin, 1968 P5 endopodal lobe outer seta longer than inner seta .......................... H. munmui sp. nov P5 endopodal lobe setae subequal or inner seta slightly longer than outer one .................. 13

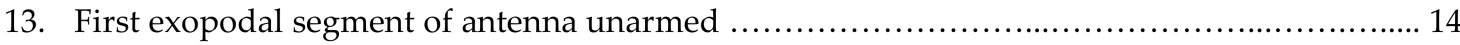
First exopodal segment of antenna with one seta ............................................. 15

14. First segment of female antennule with darkly pigmented patch ......... H. curticorne (Boeck, 1872) First segment of female antennule without such pigmented patch .............. H. langi Wells, 1967

15. Setae of P5 endopodal lobe considerably shorter than exopodal setae Setae of P5 endopodal lobe subequal or slightly shorter than exopodal setae H. arangureni Suárez-Morales and Fuentes-Reinés, 2015

Funding: This study was supported by the National Institute of Biological Resources (NIBR), funded by the Ministry of Environment (MOE) of the Republic of Korea (NIBR201902204).

Acknowledgments: The author is grateful to Wonchoel Lee (Hanyang University, Korea), the founder of MEAL (Meeting of Experts on Aquatic Life), for his kind guidance and help with this article, and Heejin Moon for her great help in drawing. I also express my sincere thanks to the two anonymous reviewers and the editor for reasonable criticism that improved the text.

Conflicts of Interest: The authors declare no conflict of interest.

\section{References}

1. Song, S.J.; Park, J.; Kwon, B.O.; Ryu, J.; Khim, J.S. Ecological checklist of the marine and brackish-water harpacticoid copepod fauna in Korean waters. Zool. Stud. 2012, 51, 1397-1410.

2. National Institute of Biological Resources. Discovery of Korean Indigenous Species (Invertebrates); NIBR: Incheon, Korea, 2019; pp. 1-4. (In Korean) 
3. Sciberras, M.; Huys, R.; Bulnes, V.N.; Cazzaniga, N.J. A new species of Halectinosoma Vervoort, 1962 (Copepoda: Harpacticoida) from Argentina, including a key to species with unusual leg armature patterns, notes on wrongly assigned taxa and an updated key to ectinosomatid genera. Mar. Biodivers. 2017, 48, 407-422. [CrossRef]

4. Kim, J.G.; Jung, T.W.; Yoon, S.M. A new species of the genus Halectinosoma (Copepoda, Harpacticoida, Ectinosomatidae) from Korea. Proc. Biol. Soc. Wash. 2017, 130, 52-74.

5. Karanovic, T.; Pesce, G.L. A new genus and species of the family Ectinosomatidae (Crustacea: Copepoda: Harpacticoida) from the groundwaters of India. Ann. de Limnol. Int. J. Limnol. 2001, 37, 281-292. [CrossRef]

6. Burgess, R. An improved protocol for separating meiofauna from sediments using colloidal silica sols. Mar. Ecol. Prog. Ser. 2001, 214, 161-165. [CrossRef]

7. Huys, R.; Gee, J.M.; Moore, C.G.; Hamond, R. Marine and Brackish Water Harpacticoid copepods. Part 1. In Synopses of the British Fauna (New Series); Field Studies Council: Shrewsbury, UK, 1996; pp. 4-19.

8. Lang, K. Monographie der Harpacticiden (Vorläufige Mitteilung); Almqvist \& Wiksells Boktryckeri Ab: Uppsala, Sweden, 1944; pp. 1-39.

9. Vervoort, W. Report on some copepoda collected during the melanesia expedition of the osaka museum of natural history. Publ. Seto Mar. Biol. Lab. 1962, 10, 393-470. [CrossRef]

10. Lang, K. Copepoda Harpacticoida from the Californian Pacific coast. K. Sven. Vetensk. Handl. 1965, 10, 1-560.

11. Huys, R. Unresolved cases of type fixation, synonymy and homonymy in harpacticoid copepod nomenclature (Crustacea: Copepoda). Zootaxa 2009, 2183, 1-99. [CrossRef]

12. Clément, M.; Moore, C.G. A revision of the genus Halectinosoma (Harpacticoida: Ectinosomatidae): A reappraisal of H. sarsi (Boeck) and related species. Zool. J. Linn. Soc. 1995, 114, 247-306.

13. Clément, M.; Moore, C.G. A revision of the genus Halectinosoma (Copepoda: Harpacticoida: Ectinosomatidae): The H. herdmani (Scott \& Scott) group of species. Zool. J. Linn. Soc. 2000, 128, 237-267.

14. Clément, M.; Moore, C.G.; And, M.C. Towards a revision of the genus Halectinosoma (Copepoda, Harpacticoida, Ectinosomatidae): New species from the North Atlantic and Arctic regions. Zool. J. Linn. Soc. 2007, 149, 453-475. [CrossRef]

15. Wells, J.B. An annotated checklist and keys to the species of Copepoda Harpacticoida (Crustacea). Zootaxa 2007, 1568, 1-872. [CrossRef]

Publisher's Note: MDPI stays neutral with regard to jurisdictional claims in published maps and institutional affiliations.

(C) 2020 by the author. Licensee MDPI, Basel, Switzerland. This article is an open access article distributed under the terms and conditions of the Creative Commons Attribution (CC BY) license (http://creativecommons.org/licenses/by/4.0/). 